\begin{tabular}{|c|c|}
\hline Title & $\begin{array}{l}\text { The Mini Nutritional A ssessment-Short Form as a predictor of nursing home mortality in Japan: A 30-month } \\
\text { longitudinal study }\end{array}$ \\
\hline Author(s) & $\begin{array}{l}\text { Motokawa, Keiko; Y asuda, Jun; Mikami, Y urie; Edahiro, A yako; Morishita, Shiho; Shirobe, Maki; Ohara, Y uki; } \\
\text { Nohara, Kanji; Hirano, Hirohiko; W atanabe, Y utaka }\end{array}$ \\
\hline Citation & $\begin{array}{l}\text { A rchives of gerontology and geriatrics, 86, UNSP } 103954 \\
\text { https:/doi.org/10.1016/.archger.2019.103954 }\end{array}$ \\
\hline Issue Date & $2020-01$ \\
\hline Doc URL & http:/hdl.handle.net/2115/80117 \\
\hline Rights & $\begin{array}{l}\text { (0) 2020. This manuscript version is made available under the CC-BY-NC-ND } 4.0 \text { license } \\
\text { http://creativecommons.org/icenses/by-nc-nd/4.0/ }\end{array}$ \\
\hline Rights(URL) & http://creativecommons.org/icenses/by-nc-nd/4.0/ \\
\hline Type & article (author version) \\
\hline File Information & A rch. Gerontol. Geriatr.86_UNSP 103954.pdf \\
\hline
\end{tabular}

Instructions for use 


\section{The Mini Nutritional Assessment-Short Form as a predictor of nursing home mortality in Japan: A 30-month longitudinal study}

Keiko Motokawa ${ }^{\mathrm{a}}$, Jun Yasuda ${ }^{\mathrm{a}}$, Yurie Mikami ${ }^{\mathrm{a}}$, Ayako Edahiro ${ }^{\mathrm{a}}$, Shiho Morishita ${ }^{\mathrm{a}}$, Maki Shirobe $^{\mathrm{a}}$, Yuki Ohara ${ }^{\mathrm{b}}$, Kanji Noharac ${ }^{\mathrm{c}}$,Hirohiko Hirano ${ }^{\mathrm{a}}$, Yutaka Watanabe ${ }^{\mathrm{d}}$

aTokyo Metropolitan Institute of Gerontology, Tokyo, Japan

${ }^{b}$ Department of Oral Health Education, Graduate School of Medical and Dental Science, Tokyo Medical and Dental University, Tokyo, Japan

'Division of Functional Oral Neuroscience, Osaka University Graduate School of Dentistry, Osaka, Japan

${ }^{\mathrm{d}}$ Gerodontology, Department of Oral Health Science, Faculty of Dental Medicine, Hokkaido University, Hokkaido, Japan

\section{Corresponding author:}

Yutaka Watanabe, PhD, Associate Professor

Gerodontology, Department of Oral Health Science,

Faculty of Dental Medicine, Hokkaido University

Nishi-7, Kita-13, Kita-ku, Sapporo, 060-8586 Japan

Tel: +8111-706-4582

Fax: +8111-706-4582

E-mail: ywata@den.hokudai.ac.jp

Abbreviations

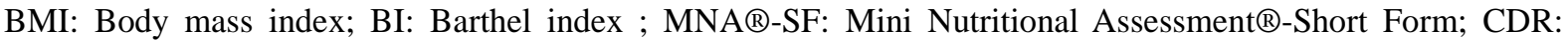
Clinical Dementia Rating; MHLW: Ministry of Health, Labour and Welfare; HR: Hazard ratio; CI: Confidence interval 


\section{Author e-mail address}

Keiko Motokawa: kikiki_1004@yahoo.co.jp Jun Yasudal: 55fhyanh@gmail.com

Yurie Mikami: ega0dm@gmail.com

Ayako Edahiro: aedahiro514@gmail.com

Shiho Morishita: morishita947@gmail.com

Maki Shirobe: mashirobe@gmail.com

Yuki Ohara: ohara.pvoh@tmd.ac.jp

Kanji Nohara: nohara@dent.osaka-u.ac.jp

Hirohiko Hirano: h-hiro@gd5.so-net.ne.jp

YutakaWatanabe: ywata@den.hokudai.ac.jp 


\section{Highlights}

- We examined residents’ MNA ${ }^{\circledR}$-SF score \& 30-month mortality in Japanese nursing homes

- $\quad$ During the study, 157 (42.8\%) participants died

- $\quad$ MNA $^{\circledR}$-SF scores were significantly lower in the deceased residents than survivors

- $\quad$ After adjusting for confounders, MNA ${ }^{\circledR}$-SF score was associated with mortality

- $\quad \mathrm{MNA}^{\circledR}$-SF is an effective predictor of mortality in nursing homes in Japan 


\section{The Mini Nutritional Assessment-Short Form as a predictor of nursing home mortality in Japan: A 30-month longitudinal study}

\section{Abstract}

Objectives: We examined whether the Mini Nutritional Assessment-Short Form (MNA ${ }^{\circledR}$ SF) predicted mortality in 367 nursing home residents (82\% women; mean age $=84.4 \pm$ 8.5 years) in Japan.

Measurements: We examined participants' basic characteristics (sex, age, height, weight, and medical history), the Barthel index (BI), clinical dementia rating (CDR), and six items of the MNA ${ }^{\circledR}$-SF. The association between the MNA ${ }^{\circledR}$-SF and 30-month mortality was assessed using a Cox proportional regression analysis.

Results: During the study, 157 (42.8\%) participants died. MNA ${ }^{\circledR}$-SF scores in the Survival group were significantly higher than in the Death group (9.4 \pm 2.1 vs. $8.4 \pm 2.3$, respectively; $p<.001)$. After adjusting for age, sex, history of aspiration pneumonia, BI, and CDR, MNA ${ }^{\circledR}$-SF scores were significantly associated with 30-month mortality

\section{Abbreviations}

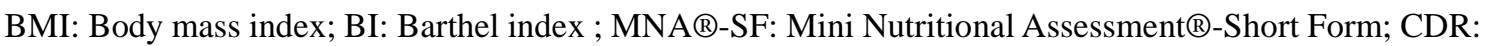
Clinical Dementia Rating; MHLW: Ministry of Health, Labour and Welfare; HR: Hazard ratio; CI: Confidence interval 
(hazard ratio: 0.89, 95\% confidence interval: 0.82-0.97, $p=.005$ ).

Conclusion: The MNA ${ }^{\circledR}$-SF was an effective predictor of mortality among nursing home residents in Japan, even after adjusting for potential confounders. These results indicate that periodically evaluating nutritional status using the MNA®-SF, and nutritional interventions according to status, may result in maintenance and improvement of nutritional status, as well as lead to reduced mortality.

Key words: Mini Nutritional Assessment, nursing home, long-term care, elderly person 


\section{Introduction}

The proportion of people over 65 years of age in Japan is increasing annually, and the number of elderly individuals who require care also continues to increase (Japanese Ministry of Health, Labour and Welfare [MHLW], 2017). Many elderly persons, who require some form of care, find it difficult to live independently, and thus enter nursing homes. However, most individuals eventually leave these nursing homes, due to reasons such as death or long-term hospitalization (MHLW, 2010). Moreover, malnutrition in the elderly has been reportedly associated with hospitalization (Correia \& Waitzberg, 2003; Lim et al., 2012) and death (Correia \& Waitzberg, 2003; Törmä, Winblad, Cederholm, \& Saletti, 2013). In other words, early detection and response to malnutrition are important.

In general, nutritional characteristics vary due to changes in physiological function with age (e.g., decreased intake of food, decreased exercise volume, decreased digestive absorption rate, mental problems, large individual differences, etc., (Sullivan, 2000)). As there is not only one cause of malnutrition, it is necessary to use indicators that include other factors. In addition, in the case of residents in facilities, it is not easy to determine malnutrition by blood examination, and it is also required that the time taken for screening be short and simple. Therefore, the Mini Nutritional Assessment $\left(\mathrm{MNA}^{\circledR}\right)$ was developed as nutritional screening tool (Vellas et al., 1999). 
Prior research comparing three malnutrition screening tools-the $\mathrm{MNA}^{\circledR}$, Nutritional Risk Screening 2002, and the Malnutrition Universal Screening Tool—found that the MNA ${ }^{\circledR}$ was the most suitable tool to predict mortality in nursing home residents (Diekmann et al., 2013). However, the $\mathrm{MNA}^{\circledR}$ involves completing a questionnaire comprising 18 items. Therefore, the MNA ${ }^{\circledR}$-Short Form (MNA ${ }^{\circledR}$-SF), which consists of six questionnaires, was developed. The validity of this measure has been confirmed for the occurrence of a variety of malnutrition-related risks in elderly persons (Guigoz, 2006). Prior research investigating concordance between the MNA ${ }^{\circledR}$-SF and MNA ${ }^{\circledR}$ for nursing home residents has confirmed its validity (Kaiser et al., 2011).

Although many previous studies were reported to predict mortality using MNA ${ }^{\circledR}$ (Lundin et al., 2012;Saletti et al., 2005;Persson et al., 2002;Kagansky et al., 2005;Tsai and Ku, 2008; Tsai et al., 2010), few used MNA ${ }^{\circledR}$-SF. Ulger et al. (2013) observed 534 nursing home residents in Turkey over 18 months and reported that 22.1\% (118 participants) died over the study period. Those who were malnourished had significantly higher mortality than those who were at risk of malnutrition or who had normal nutritional status. However, this study did not perform the Kaplan-Meier analysis nor the Cox proportional regression analysis. Lilamand et al. (2015) reported, in their study of 773 nursing home residents in France, that the $\mathrm{MNA}^{\circledR}$-SF demonstrated significant predictive 
capabilities of mortality over a one-year period. Nevertheless, no research with an observation period of one year or longer has been performed in Japan using the MNA ${ }^{\circledR}$-SF to evaluate residents' nutritional state to predict mortality. Furthermore, while a systematic review has reported that nutritional state, physical functions, and cognitive functions are associated with mortality in elderly individuals requiring care (Thomas et al., 2013), no report including all these items has been performed.

Nursing homes in Japan are facilities where many residents have difficulty walking independently and need assistance with ADL, and it is reported that about $70 \%$ of residents had dementia that affected their daily life (Japanese Ministry of Health, 2017). Moreover, in the previous studies, it has been reported that the rate of eating difficulties among elderly people with dementia who live in nursing homes is as high as 80\% (Edahiro et al., 2012). Eating difficulties might lead to decrease intake of food, leading to malnutrition. If it becomes clear that prediction of mortality evaluation of nutritional status using MNA-SF is effective even after adjusting for other factors related to death, it would be possible to implement nutritional care according to each hierarchy as well as early nutritional care.

Therefore, this study established an observation period of 30-month and investigated whether the evaluation of nutritional state, using the $\mathrm{MNA}^{\circledR}-\mathrm{SF}$, is an effective tool for predicting mortality in elderly individuals living in nursing homes in Japan. 


\section{Materials and Methods}

\subsection{Study design and participants}

We explained the survey to residents and their guardians at five nursing homes (maximum capacity of 436 residents) operated by the same corporation in the Aichi Prefecture, Japan; then, we obtained participants' or their family members' written consent for participation and analyzed the data of 423 persons (333 women), all of whom ingested food orally. We collected information on participants' death for 30 months. We could not collect information on the death events of 56 participants due to moves to other facilities or lengthy hospitalizations; thus, we analyzed the data of 367 participants (Figure 1). We then divided the participants into two groups: Death group and Survival group. This study was performed after review by and approval (No. 605) from the Ethics and Conflict of Interest Committee of the National Center for Geriatrics and Gerontology, Japan. 


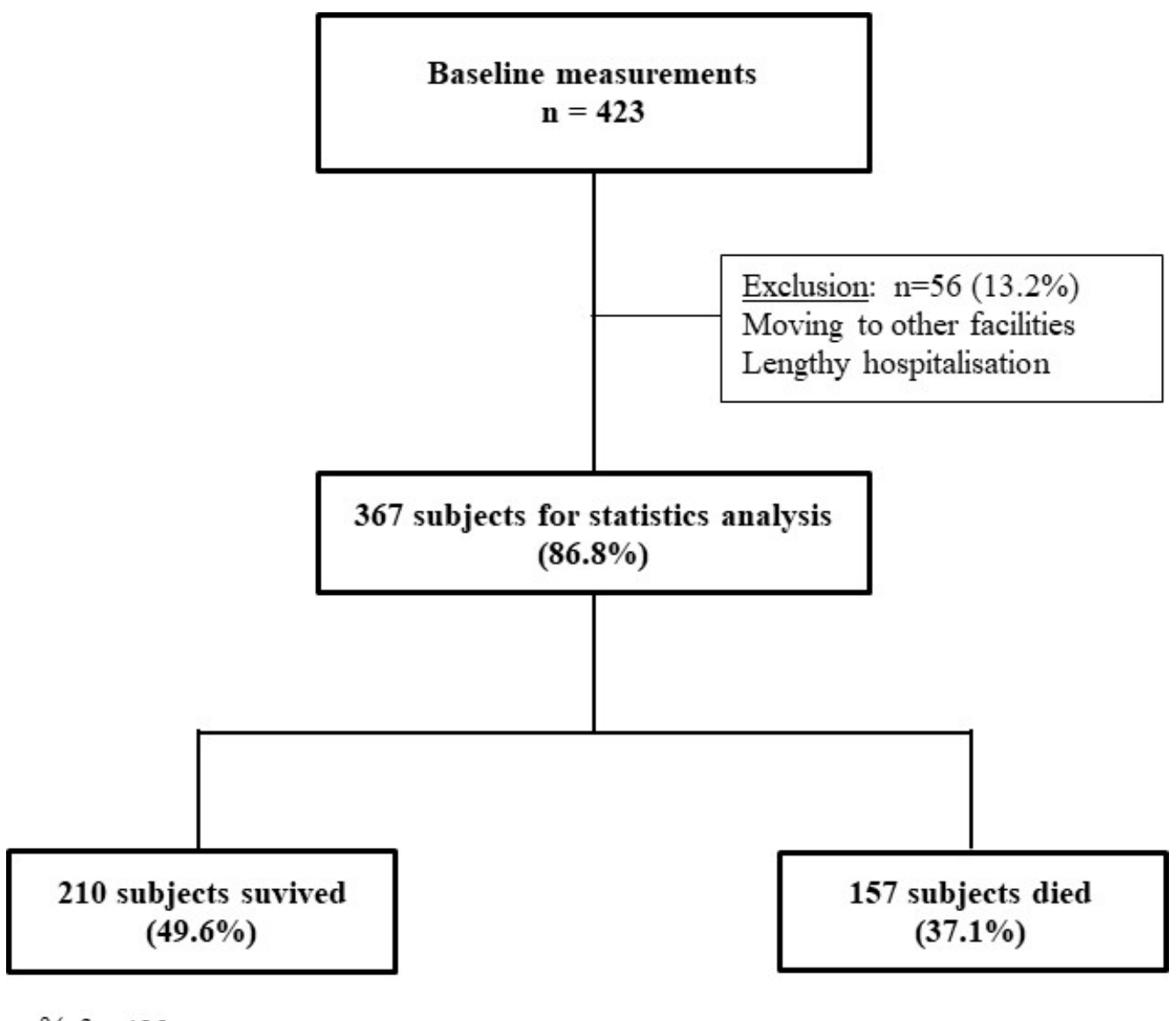

$\%$ for 423

Figure 1. Data collection for 30 months

\subsection{Survey Items}

With October 2012 as baseline, lectures and training were conducted regarding evaluation of survey items with all nurses, care workers, and dieticians of the facilities, to ensure uniformity of evaluation criteria. Thereafter, survey forms for each participant were distributed among the nurses, care workers, and dieticians in charge, who, in turn, performed the survey, collecting basic data (sex, age, height, and weight), medical history (aspiration pneumonia, cerebrovascular disease, respiratory illness, circulatory disturbance, neoplastic 
disease, Parkinson's disease, and neurological disease [excludes dementia and Parkinson’s disease]), Barthel index (BI) to assess physical functions, clinical dementia rating (CDR) to assess cognitive functions, and the MNA ${ }^{\circledR}$-SF to assess nutritional state. Body mass index (BMI) was also calculated using data about height and weight.

\subsubsection{BI}

$\mathrm{BI}$ is used to evaluate physical functions of daily life. It comprises 10 items specifying daily life activities: feeding, transfers (bed to chair and back), grooming, toilet use, bathing, mobility (on level surfaces), stairs, dressing, bowels, and bladder control. For each item, an assessment is made of the extent of need for care assistance (Mahoney \& Barthel, 1965). Total scores range from 0 to 100, with higher scores indicating a better ability to independently perform daily activities.

\subsubsection{CDR}

CDR evaluations were made by a physician who specialized in cognition based on the methods of Morris (1993). The CDR has five grades (0, 0.5, 1, 2, and 3), with grades assigned for six items: memory, orientation, judgment and problem solving, community affairs, home and hobbies, and personal care. In this measure, higher grades 
are indicative of a more severe cognitive disorder.

\subsection{3 $M N A^{\circledR}-S F$}

The MNA ${ }^{\circledR}$-SF (Rubenstein, 2001) comprises six items: decrease in food intake over the past 3 months (severe, moderate, and no decrease in food intake), weight loss over the past 3 months (does not know, weight loss greater than $3 \mathrm{~kg}$, weight loss between 1 and $3 \mathrm{~kg}$, and no weight loss), mobility (bed- or chair-bound, able to get out of bed/chair but does not go out, and goes out), acute disease or psychological stress over the past 3 months (yes or no), neuropsychological problems (severe dementia or depression, mild dementia, and no psychological problems), BMI (less than 19, 19 to less than 21, 21 to less than 23, and 23 or greater). Total scores for the MNA ${ }^{\circledR}$-SF range from 0 to 14 points, with higher scores indicative of a better nutritional state. MNA ${ }^{\circledR}$-SF scores are also classified into three categories: normal nutritional state (12-14 points), at risk of malnutrition (8-11 points), and malnourished (0-7 points).

\subsection{Statistical analyses}

We analyzed the data of 367 participants. Values are expressed as mean \pm standard deviation, or number of persons (\%). For between-group comparisons of Death 
and Survival groups, Mann-Whitney U tests were conducted for continuous variables, and chi-square tests for categorical values. In addition, since BMI was included in the MNA $^{\circledR}$-SF item, a strong correlation $(r=0.606)$ was recognized and it was excluded from subsequent analyses.

The association between $\mathrm{MNA}^{\circledR}$-SF scores and 30-month mortality was analyzed using the Kaplan-Meier analysis (log-rank test). To confirm the association between mortality and each confounding factor reported in prior studies, and investigate the association of the $\mathrm{MNA}^{\circledR}$-SF with predictors of mortality, we performed a Cox proportional regression analysis (Model 1: age and sex; Model 2: Model $1+$ presence of aspiration pneumonia, BI, and CDR).

Missing values were confirmed from 1.1\% (BI) to 15.8\% (history of aspiration pneumonia). To minimize deficit bias, multiple imputation was utilized, based on the missing at random process, and the missing values were complemented (Barnard \& Meng, 1999; Vandenbroucke et al., 2007). Five datasets were created by incorporating the missing values. After independent performance of multivariate multiple regression and logistic regression analyses on each dataset, the results were integrated for assumptions.

The primary analysis utilized complementary data via multiple imputation, and the secondary analysis utilized complete data from which missing data were excluded. 
Significance was defined as $p<.05$. All analyses were performed with SPSS 23.0 (IBM SPSS for Windows, SPSS Japan).

\section{Results}

During the observation period, 157 persons (42.8\%) died. In the MNA ${ }^{\circledR}$-SF categories at baseline, 86 persons (23.4\%) were malnourished, 235 (64.0\%) were at risk of malnutrition, and 46 (12.5\%) displayed a normal nutritional state (Table 1).

As shown in Table 1, the Death group was significantly older and had higher CDR than did the Survival group, while weight, BI scores, and MNA ${ }^{\circledR}$-SF scores were significantly lower in the Death group than the Survival group. Further, the Death group had significantly more cases of aspiration pneumonia history than did the Survival group. As for the results of MNA ${ }^{\circledR}$-SF categories, malnourished individuals were significantly more in the Death group than the Survival group.

Table 1. Baseline characteristics $(\mathrm{N}=367)$

\begin{tabular}{lccc}
\hline Variables & Survival $(\mathrm{n}=210)$ & Death $(\mathrm{n}=157)$ & $p$ \\
\hline Age (years) & $83.0 \pm 8.6$ & $86.4 \pm 7.9$ & $<.001$ \\
Women & $174(82.9)$ & $127(80.9)$ & \\
Men & $36(17.1)$ & $30(19.1)$ & .363 \\
Observation period (days) & $802 \pm 159$ & $382 \pm 229$ & $<.001$ \\
Height $(\mathrm{cm})$ & $146.7 \pm 8.9$ & $145.9 \pm 9.5$ & .366
\end{tabular}




\begin{tabular}{|c|c|c|c|}
\hline Weight (kg) & $45.2 \pm 8.9$ & $41.7 \pm 8.0$ & $<.001$ \\
\hline $\operatorname{BMI}\left(\mathrm{kg} / \mathrm{m}^{2}\right)$ & $21.0 \pm 3.6$ & $19.6 \pm 3.3$ & $<.001$ \\
\hline \multicolumn{4}{|l|}{ Medical history $(\mathrm{N}=309)$} \\
\hline Aspiration pneumonitis & $11(6.6)$ & $21(14.8)$ & .024 \\
\hline Cerebrovascular disorder & $87 \quad(52.1)$ & $80(56.3)$ & .493 \\
\hline Respiratory disease & $16(9.6)$ & $17(12.0)$ & .580 \\
\hline Circulatory disorder & $84(50.3)$ & $66(46.5)$ & .568 \\
\hline Neoplastic disease & $17 \quad(10.2)$ & $12(8.5)$ & .697 \\
\hline Parkinson disease & $17 \quad(10.2)$ & $6(4.2)$ & .052 \\
\hline Neurological disorder & $11(6.6)$ & $7(4.9)$ & .630 \\
\hline BI scores $(\mathrm{N}=363)$ & $42.0 \pm 27.5$ & $32.1 \pm 28.8$ & $<.001$ \\
\hline \multicolumn{4}{|l|}{ CDR } \\
\hline 0 & $12(5.7)$ & $1(0.6)$ & \\
\hline 0.5 & $20(9.5)$ & $17(10.8)$ & \\
\hline 1 & $51(24.3)$ & $16(10.2)$ & $<.001$ \\
\hline 2 & $43(20.5)$ & $34(21.7)$ & \\
\hline 3 & $84(40.0)$ & $89(56.7)$ & \\
\hline MNA $^{\circledR}$-SF scores & $9.4 \pm 2.1$ & $8.4 \pm 2.3$ & $<.001$ \\
\hline \multicolumn{4}{|l|}{ MNA $^{\circledR}$-SF categories } \\
\hline Normal nutritional status & $33(15.7)$ & $13(8.3)$ & \\
\hline At risk of malnutrition & $142(67.6)$ & $93(59.2)$ & .001 \\
\hline Malnourished & $35 \quad(16.7)$ & $51(32.5)$ & \\
\hline
\end{tabular}

Continuous variables are expressed as mean $\pm \mathrm{SD}$, and were analyzed with MannWhitney U test. Categorical variables are given as numbers (percentage), and were analyzed by chi-square tests. $p<.05$ is defined as a significant difference between Survival and Death groups. BMI, body mass index; BI, Barthel index; CDR, clinical dementia rating, MNA ${ }^{\circledR}$-SF, Mini Nutritional Assessment-Short Form

Figure 2 indicates the survival curve, exploring the association between MNA ${ }^{\circledR}$ SF category and 30-month mortality. The mortality risk for participants with malnutrition was significantly higher than that for those with other MNA ${ }^{\circledR}$-SF categories (log-lank 
test: $p<.001)$.

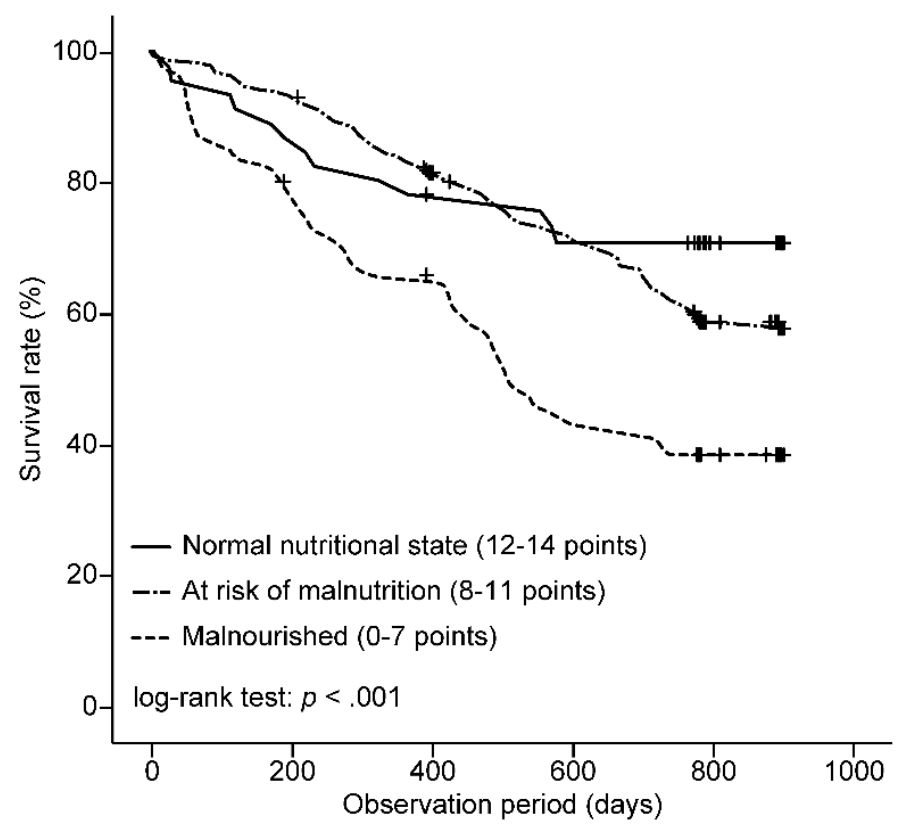

Figure 2. Survival curve of MNA ${ }^{\circledR}$-SF category with 30-month mortality

MNA ${ }^{\circledR}$-SF, the Mini Nutritional Assessment-Short Form.

After adjusting for sex and age in Model 1, MNA ${ }^{\circledR}$-SF scores significantly predicted participants’ 30-month mortality (hazard ratio [HR]: 0.85, 95\% confidence interval [CI]: 0.80-0.92; Table 2). Further, even after adjusting for sex, age, aspiration pneumonia, BI scores, and CDR, MNA ${ }^{\circledR}$-SF scores in Model 2 remained significantly associated with 30-month mortality (HR: 0.89, 95\% CI: 0.82-0.97). 
Table 2. Association of MNA ${ }^{\circledR}$-SF scores with 30-month mortality

\begin{tabular}{|c|c|c|c|c|c|c|c|c|c|c|c|c|c|c|}
\hline \multirow[b]{3}{*}{ Age } & \multicolumn{5}{|c|}{ Crude } & \multicolumn{4}{|c|}{ Model 1} & \multicolumn{5}{|c|}{ Model 2} \\
\hline & \multirow{2}{*}{$\begin{array}{c}\text { HR } \\
1.04\end{array}$} & \multicolumn{3}{|c|}{$95 \% \mathrm{CI}$} & \multirow{2}{*}{$\begin{array}{c}p \\
<.001\end{array}$} & \multirow{2}{*}{$\begin{array}{c}\text { HR } \\
1.04\end{array}$} & \multicolumn{2}{|c|}{$95 \%$ CI } & \multirow{2}{*}{$\begin{array}{c}p \\
<.001\end{array}$} & \multirow{2}{*}{$\begin{array}{c}\text { HR } \\
1.04\end{array}$} & \multicolumn{3}{|c|}{$95 \%$ CI } & \\
\hline & & ( 1.02 & -1.06 & ) & & & $(1.02$ & $-1.06)$ & & & $(1.02$ & -1.06 & & \\
\hline Sex (1: Men, 2: Women) & 0.86 & $(0.58$ & $-\quad 1.28$ & ) & .462 & 0.62 & $(0.41$ & - 0.94$)$ & .025 & 0.62 & $(0.40$ & - 0.95 & ) & .027 \\
\hline Aspiration pneumonia & 1.88 & $(1.14$ & - 3.10 & ) & .014 & & & & & 1.83 & ( 1.08 & - $\quad 3.11$ & ) & .024 \\
\hline BI scores & 0.99 & $(0.98$ & - $\quad 1.00$ & ) & .001 & & & & & 1.00 & ( 0.99 & - 1.01 & ) & .497 \\
\hline \multicolumn{15}{|l|}{ CDR } \\
\hline 0 & \multicolumn{5}{|c|}{ Reference } & & & & & \multicolumn{5}{|c|}{ Reference } \\
\hline 0.5 & 8.55 & ( 1.14 & - 64.27 & & .037 & & & & & 7.53 & $(0.99$ & -56.82 & ) & .050 \\
\hline 1 & 3.56 & ( 0.47 & - 26.86 & 7 & .218 & & & & & 2.52 & ( 0.33 & - 19.16 & ) & .371 \\
\hline 2 & 8.01 & $(1.10$ & - 58.52 & ) & .040 & & & & & 5.51 & $(0.75$ & -40.79 & ) & .094 \\
\hline 3 & 9.69 & ( 1.35 & - 69.58 & ) & .024 & & & & & 5.67 & $(0.77$ & -41.77 & ) & .089 \\
\hline MNA $^{\circledR}$-SF scores & 0.85 & $(0.79$ & - $\quad 0.91$ & ) & $<.001$ & 0.85 & $(0.80$ & - 0.92$)$ & $<.001$ & 0.89 & ( 0.82 & - $\quad 0.97$ & ) & .005 \\
\hline
\end{tabular}

HR, hazard ratio; CI, confidence interval; BI, Barthel index; CDR, clinical dementia rating; MNA ${ }^{\circledR}$-SF, the Mini Nutritional AssessmentShort Form. Model 1 was adjusted for sex and age. Model 2 was adjusted for Model 1 plus aspiration pneumonia, BI, and CDR. $p<.05$ was considered a significant association. 
While a wider CI and lower accuracy were confirmed as characteristics of the analysis, comparison of complete data and data adjusted with multiple imputation yielded similar results. Further, the variability of the five-time imputation, incorporated in the primary analyses, was less than $10 \%$ (data not shown).

\section{Discussion}

In this study, even after controlling for explanatory variables reported as strong predictors of mortality in nursing homes — sex and age (Eren et al., 2015; Hjaltadottir, Hallberg, Ekwall, \& Nyberg, 2011), history of aspiration pneumonia (van der MaarelWierink et al., 2015), BI (Díez-Manglano et al., 2016), and CDR (Beeri et al., 2008)— MNA $^{\circledR}$-SF scores effectively predicted the 30-month mortality of nursing home residents in Japan.

The mortality rate in the 30-month observation period of the current sample was 42.8\%. This is similar to mortality rates of elderly persons requiring care found in prior research: 17.4\% after 1 year (Lilamand et al., 2015), 30.7\% after 2 years (Izawa, Enoki, Hasegawa, Hirose, \& Kuzuya, 2014), and 50.0\% after 3 years (Fernandez \& Lapane, 2002). Additionally, the current data revealed that $23.4 \%$ participants were malnourished 
and $64.0 \%$ were at risk of malnutrition. In a study by Lilamand et al. (2015), 15.7\% nursing home residents were malnourished, and 58.7\% were at risk of malnutrition. In a research in Japan, Izawa et al. (2014) reported that 19.9\% were malnourished and $60.2 \%$ were at risk of malnutrition. While this study had a somewhat high percentage of malnourished individuals, roughly similar rates were shown. We believe that these results show the generality of our participants and the validity of the MNA ${ }^{\circledR}$-SF evaluations. In addition, as expected, the Death group in our study differed significantly per age, cases of aspiration pneumonia history, CDR scores, BI, and MNA ${ }^{\circledR}$-SF scores compared to the Survival group. This also indicates the generality of our participants based on prior studies (Beeri et al., 2008; Díez-Manglano et al., 2016; Eren et al., 2015; Hjaltadottir et al., 2011; van der Maarel-Wierink et al., 2015).

The observational period in this study was long. Additionally, few studies have investigated the association between MNA ${ }^{\circledR}$-SF and mortality in Japan; thus, marking this study's significance. Malnutrition has been reported to be associated with mortality (Correia \& Waitzberg, 2003; Törmä, Winblad, Cederholm, \& Saletti, 2013), and periodic assessment of nutritional status is important. In everyday practice of nursing home, it would be desirable to have an assessment tool where not only residents but even evaluators are not burdened. Furthermore, it would need to be able to evaluate not only 
professionals but everybody. The MNA ${ }^{\circledR}$-SF is a simple questionnaire of 6 items that can be completed in a shorter time than the MNA ${ }^{\circledR}$, which consists of 18 items. In addition, it is possible for care workers to evaluate the questionnaire. Therefore, the evaluation of nutritional status using MNA ${ }^{\circledR}$-SF is less burdensome and might well predict death.

In an intervention study in prior research, an oral supplement (approximately 400 kcal/daily) was provided for a two-month period to nursing home residents; while the Non-supplement group had no changes, the Supplement group had significant increases in energy intake amounts, body weight, and MNA ${ }^{\circledR}$ scores (Lauque et al., 2000). Similarly, an intervention study involving protein supplements (250 kcal energy, 9.5 g protein) given to nursing home residents for a six-month period also reported significant increases in the Supplement group, not only concerning body weight, but also for BMI (Lee et al., 2013). However, these studies used the $\mathrm{MNA}^{\circledR}$, and there is no report concerning the $\mathrm{MNA}^{\circledR}$-SF as a nutritional outcome in nursing homes. Therefore, future studies should examine the effects of nutrition interventions using the $\mathrm{MNA}^{\circledR}-\mathrm{SF}$.

The current study had several limitations. First, the results might not be generalizable to elderly people in nursing homes in other regions, because only five institutions from a limited geographical area were selected for the survey. Second, as we did not study biological markers (e.g., albumin levels; Zuliani et al., 2004) for deaths in 
nursing homes, future studies should include these markers in their investigations. However, a five-year cohort study has reported that albumin levels are not associated as significant mortality predictors (Veronese et al., 2013). Albumin levels may not be a useful long-term mortality predictor. Furthermore, we have not investigated specific diseases like stroke, heart failure, hypertension, diabetic mellitus, and dementia. Additionally, it is possible that the evaluation criteria of each index used in the current study were not perfectly uniform. This is because multiple persons, such as dieticians, nurses, and care workers, had recorded responses at five separate facilities.

In conclusion, we elucidated that the $\mathrm{MNA}^{\circledR}$-SF was an effective tool for predicting 30-month mortality in nursing home residents in Japan. These results indicate that periodically evaluating the nutritional status using the MNA ${ }^{\circledR}-\mathrm{SF}$, and the provision of nutritional intervention according to the status may result in maintenance and improvement of the nutritional status, which in turn will lead to reduced mortality.

\section{Acknowledgments}

We are grateful for the collaboration of the Nishikasugai Fukushikai Social Welfare Corporation and the incorporated public interest group-the Aichi Prefecture Dental Hygienists’ Association. 


\section{Funding sources}

This study was supported by Grants-in-Aid from the Research Committee of Comprehensive Research on Aging and Health, the Ministry of Health, Labour and Welfare of Japan (H27-Choju-Ippan-005) and Research Funding for Longevity Sciences (24-21) from the National Center for Geriatrics and Gerontology, Japan. Additional support was received from JSPS KAKENHI [grant number JP16K11908]. These sources had no role in the design, methods, recruitment, data collection, analysis, or preparation of the paper.

\section{Declarations of interest}

None

\section{Statement of Authorship}

KM, YW, and JY designed the study. KM, JY, SM, and MS collected the data. JY, AE, and YM performed statistical analyses. KM, JY, YM, and YW wrote the paper. $\mathrm{YO}, \mathrm{KN}$, and $\mathrm{HH}$ supervised the study conduct and performed a final revision of the manuscript. All authors approved the final manuscript. 


\section{References}

Barnard, J., \& Meng, X. L. (1999). Applications of multiple imputation in medical studies: From AIDS to NHANES. Statistical Methods in Medical Research, 8, 1736. doi: 10.1177/096228029900800103

Beeri, M. S., Silverman, J. M., Schmeidler, J., Wysocki, M., Grossman, H. Z., Purohit, D. P., ... \& Haroutunian, V. (2008). Clinical dementia rating performed several years prior to death predicts regional Alzheimer's neuropathology. Dementia and Geriatric Cognitive Disorders, 25(5), 392-398. doi: 10.1159/000122586

Correia, M. I., \& Waitzberg, D. L. (2003). The impact of malnutrition on morbidity, mortality, length of hospital stay and costs evaluated through a multivariate model analysis. Clinical Nutrition, 22, 235-239. doi: 10.1016/S0261-5614(02)00215-7

Diekmann, R., Winning, K., Uter, W., Kaiser, M. J., Sieber, C. C., Volkert, D., \& Bauer, J. M. (2013). Screening for malnutrition among nursing home residents-a comparative analysis of the mini nutritional assessment, the nutritional risk screening, and the malnutrition universal screening tool. Journal of Nutrition, Health and Aging, 17, 326-331. doi: 10.1007/s12603-012-0396-2

Díez-Manglano, J., del Corral Beamonte, E., Ibáñez, R. R., Aranda, M. P. L., Miazza, C. T., Roldán, M. D. M. R., ... \& de Escalante Yangüela, B. (2016). [Reliability of 
the PROFUND index to predict 4-year mortality in polypathological patients]. Medicina Clínica, 147(6), 238-244. doi: 10.1016/j.medcli.2016.06.003

Edahiro, A., Hirano, H., Yamada, R., Chiba, Y., Watanabe, Y., Tonogi, M., Yamane, G. Y. (2012). "Factors affecting independence in eating among elderly with Alzheimer's disease." Geriatr Gerontol Int 12(3): 481-490.

Eren, Z., Kucukardali, Y., Ozturk, M. A., Kucukardali, B., Kaspar, E. C., \& Kantarci, G. (2015). Prevalence, associated factors and impact on mortality of chronic kidney disease in nursing home residents: A single-center experience. Geriatric \& Gerontology International, 15, 715-720. doi: 10.1111/ggi.12337

Fernandez, H. H., \& Lapane, K. L. (2002). Predictors of mortality among nursing home residents with a diagnosis of Parkinson’s disease. Medical Science Monitor, 8(4), CR241-CR246.

Guigoz, Y. (2006). The Mini Nutritional Assessment (MNA) review of the literatureWhat does it tell us? Journal of Nutrition, Health and Aging, 10, 466-485.

Hjaltadottir, I., Hallberg, I. R., Ekwall, A. K., \& Nyberg, P. (2011). Predicting mortality of residents at admission to nursing home: A longitudinal cohort study. BMC Health Services Research, 11, 86. doi: 10.1186/1472-6963-11-86

Izawa, S., Enoki, H., Hasegawa, J., Hirose, T., \& Kuzuya, M. (2014). Factors associated 
with deterioration of mini nutritional assessment-short form status of nursing home residents during a 2-year period. Journal of Nutrition, Health and Aging, 18, 372-377. doi: 10.1007/s12603-013-0400-5

Japan Ministry of Health, Labour and Welfare. (2010). The current situation and the future direction of the long-term care insurance system in Japan: With a focus on the housing for the elderly. Retrieved from http://www.mhlw.go.jp/english/database/db-hss/siel-2010.html.

Japan Ministry of Health, Labour and Welfare. (2017). Annual health, labour, and welfare report. Retrieved from https://www.mhlw.go.jp/english/wp/wphw11/dl/summary.pdf.

Japanese Ministry of Health, Labour and Welfare. (2017). The situation of residents in long-term care insurance facilities. Retrieved from https://www.mhlw.go.jp/toukei/saikin/hw/kaigo/service16/dl/kekkagaiyou_05.pdf

Kagansky, N., Berner, Y., Koren-Morag, N., Perelman, L., Knobler, H., Levy, S. (2005). "Poor nutritional habits are predictors of poor outcome in very old hospitalized patients." Am J Clin Nutr 82(4): 784-791; quiz 913-784.

Kaiser, M. J., Bauer, J. M., Uter, W., Donini, L. M., Stange, I., Volkert, D., ... \& Sieber, 
C. C. (2011). Prospective validation of the modified mini nutritional assessment short-forms in the community, nursing home, and rehabilitation setting. Journal of the American Geriatrics Society, 59, 2124-2128. doi: 10.1111/j.15325415.2011.03659.x

Lauque, S., Arnaud-Battandier, F., Mansourian, R., Guigoz, Y., Paintin, M., Nourhashemi, F., \& Vellas, B. (2000) Protein-energy oral supplementation in malnourished nursing-home residents. A controlled trial. Age and Ageing, 29, 51-56. doi: 10.1093/ageing/29.1.51

Lee, L. C., Tsai, A. C., Wang, J. Y., Hurng, B. S., Hsu, H. C., \& Tsai, H. J. (2013). Needbased intervention is an effective strategy for improving the nutritional status of older people living in a nursing home: a randomized controlled trial. International Journal of Nursing Studies, 50, 1580-1588. doi: 10.1016/j.ijnurstu.2013.04.004

Lilamand, M., Kelaiditi, E., Demougeot, L., Rolland, Y., Vellas, B., \& Cesari, M. (2015). The Mini Nutritional Assessment-Short Form and mortality in nursing home residents—results from the INCUR study. Journal of Nutrition, Health and Aging, 19, 383-388. doi: 10.1007/s12603-014-0533-1

Lim, S. L., Ong, K. C., Chan, Y. H., Loke, W. C., Ferguson, M., \& Daniels, L. (2012). Malnutrition and its impact on cost of hospitalization, length of stay, readmission 
and 3-year mortality. Clinical Nutrition, 31, 345-350 doi: 10.1016/j.clnu.2011.11.001

Lundin, H., Saaf, M., Strender, L. E., Mollasaraie, H. A., Salminen, H. (2012). "Mini nutritional assessment and 10-year mortality in free-living elderly women: a prospective cohort study with 10-year follow-up." Eur J Clin Nutr 66(9): 10501053.

Mahoney, F. I., \& Barthel, D. W. (1965). Functional evaluation: The Barthel Index. Maryland State Medical Journal, 14, 61-65

Morris, J. C. (1993). The Clinical Dementia Rating (CDR): Current version and scoring rules. Neurology, 43, 2412-2414. doi: 10.1212/WNL.43.11.2412-a

Persson, M. D., Brismar, K. E., Katzarski, K. S., Nordenstrom, J., Cederholm, T. E. (2002). "Nutritional status using mini nutritional assessment and subjective global assessment predict mortality in geriatric patients." J Am Geriatr Soc 50(12): 19962002.

Rubenstein, L. Z., Harker, J. O., Salva, A., Guigoz, Y., Vellas, B. (2001). "Screening for undernutrition in geriatric practice: developing the short-form mini-nutritional assessment (MNA-SF)." J Gerontol A Biol Sci Med Sci 56(6): M366-372.

Saletti, A., Johansson, L., Yifter-Lindgren, E., Wissing, U., Osterberg, K., Cederholm, T. 
(2005). "Nutritional status and a 3-year follow-up in elderly receiving support at home." Gerontology 51(3): 192-198.

Sullivan, D. H. (2000). Annals of Long-Term Care 8: 41-46.

Tsai, A. C. and P. Y. Ku (2008). "Population-specific Mini Nutritional Assessment effectively predicts the nutritional state and follow-up mortality of institutionalized elderly Taiwanese regardless of cognitive status." Br J Nutr 100(1): 152-158.

Tsai, A. C., Yang, S. F., Wang, J. Y. (2010). "Validation of population-specific MiniNutritional Assessment with its long-term mortality-predicting ability: results of a population-based longitudinal 4-year study in Taiwan." Br J Nutr 104(1): 93-99.

Thomas, J. M., Cooney, L. M., \& Fried, T. R. (2013). Systematic review: health-related characteristics of elderly hospitalized adults and nursing home residents associated with short-term mortality. Journal of the American Geriatrics Society, 61, 902-911. doi: 10.1111/jgs.12273

Törmä, J., Winblad, U., Cederholm, T., \& Saletti, A. (2013). Does undernutrition still prevail among nursing home residents? Clinical Nutrition, 32, 562-568. doi: 10.1016/j.clnu.2012.10.007

Ulger, Z., Halil, M., Cankurtaran, M., Yavuz, B. B., Yesil, Y., Kuyumcu, M. E., Gungor, 
E., Izgi, H., Iskit, A. T., Abbasoglu, O., Ariogul, S. (2013). "Malnutrition in Turkish nursing homes: a correlate of short term mortality." J Nutr Health Aging 17(4): 305-309.

van der Maarel-Wierink, C. D., van der Putten, G. J., De Visschere, L. M., Bronkhorst, E. M., de Baat, C., \& Schols, J. M. (2015). Risk of aspiration in care home residents and associated factors. Journal of Gerontology Nursing, 41, 26-31. doi: 10.3928/00989134-20140807-99

Vandenbroucke, J. P., Von Elm, E., Altman, D. G., Gøtzsche, P. C., Mulrow, C. D., Pocock, S. J., ... \& Egger, M. (2007). Strengthening the Reporting of Observational Studies in Epidemiology (STROBE): Explanation and elaboration. Epidemiology, 18(6), 805-835. doi: 10.1097/EDE.0b013e3181577511

Vellas, B., Guigoz, Y., Garry, P. J., Nourhashemi, F., Bennahum, D., Lauque, S., Albarede, J. L. (1999). "The Mini Nutritional Assessment (MNA) and its use in grading the nutritional state of elderly patients." Nutrition 15(2): 116-122.

Veronese, N., De Rui, M., Toffanello, E. D., De Ronch, I., Perissinotto, E., Bolzetta, F., ... \& Sergi, G. (2013). Body mass index as a predictor of all-cause mortality in nursing home residents during a 5-year follow-up. Journal of the American Medical Directors Association, 14(1), 53-57. doi: 10.1016/j.jamda.2012.09.014 
Zuliani, G., Volpato, S., Romagnoni, F., Soattin, L., Bollini, C., Leoci, V., \& Fellin, R. (2004). Combined measurement of serum albumin and high-density lipoprotein cholesterol strongly predicts mortality in frail older nursing-home residents. Aging Clinical and Experimental Research, 16(6), 472-475. doi: 10.1007/BF03327404 